Supporting Information for

\title{
Cation Radicals of Hachimoji Nucleobases $P$ and $Z$. Generation in the Gas Phase and Characterization by UV-Vis Photodissociation Action Spectroscopy and Theory
}

Shu R. Huang, František Tureček*

Department of Chemistry, Bagley Hall, Box 351700, University of Washington, Seattle, WA 98195-1700, USA

E-mail: turecek@uw.edu

\section{List of Contents}

Figure S1. Electronic transitions in (a) $\mathbf{P 1}^{+\bullet}$ and (b) $\mathbf{P 4}{ }^{+\bullet}$ calculated by EOMCCSD/6-31+G(d,p) (blue lines) and TD-DFT M06-2X/6-31+G(d,p) (brown lines).

Figure S2. Electronic transitions in (a) $\mathbf{Z 1}^{+\bullet}$ and (b) $\mathbf{Z 2}^{+\bullet}$ calculated by EOMCCSD/6$31+\mathrm{G}(\mathrm{d}, \mathrm{p})$ (blue lines) and TD-DFT M06-2X/6-31+G(d,p) (brown lines).

Figure S3. Electrospray mass spectra of aqueous-acetonitrile solutions of equimolar mixtures of $\mathrm{Cu}\left(\mathrm{NO}_{3}\right)_{2}, 2: 2^{\prime}, 6^{\prime}: 2^{\prime \prime}$-terpyridine (tpy), and (a) imidazo[1,2-a]-1,3,5-triazine (P) and (b) 6-amino5-nitro-(1H)pyrid-2-one $(\mathrm{Z})$.

Figure S4. (a) CID-MS ${ }^{3}$ spectrum of $\mathrm{D}_{3}-\mathbf{P}^{+\bullet}$; (b) UVPD (270 nm)-MS ${ }^{3}$ spectrum of $\mathrm{D}_{3}-\mathbf{P}^{+\bullet}$; (c) CID-MS ${ }^{3}$ spectrum of $\mathrm{D}_{3}-\mathbf{Z}^{+\bullet}$; (d) UVPD (270 nm)-MS ${ }^{3}$ spectrum of $\mathrm{D}_{3}-\mathbf{Z}^{+} \bullet$.

Figure S5. (a) Action spectrum of $(\mathrm{P}+\mathrm{H})^{+}$at $m / z$ 152. (b) UVPD-MS ${ }^{2}$ spectrum of $(\mathrm{P}+\mathrm{H})^{+}$at $270 \mathrm{~nm}$. (c) CID-MS ${ }^{2}$ spectrum of $(\mathrm{P}+\mathrm{H})^{+}$.

Figure S6. (a) Action spectrum of $(\mathrm{Z}+\mathrm{H})^{+}$at $m / z$ 156. (b) UVPD-MS ${ }^{2}$ spectrum of $(\mathrm{Z}+\mathrm{H})^{+}$at $300 \mathrm{~nm}$. (c) CID-MS ${ }^{2}$ spectrum of $(\mathrm{Z}+\mathrm{H})^{+}$.

Figure S7. Molecular-orbital representation of excited states and electron transitions in $\mathbf{P 1}^{+\bullet}$ (left panel) and $\mathbf{Z 1}^{+\bullet}$ (right panel). Excitation energies and oscillator strength data are from M062X/6-31+G(d,p) TD-DFT calculations.

Figure S8. (a) RRKM unimolecular rate constants $\left(\log k, \mathrm{~s}^{-1}\right)$ for the forward $\left(k_{1}\right)$ and reverse $\left(k_{-1}\right)$ isomerization of $\mathbf{Z 1}^{+\bullet}$ to $\mathbf{Z 2}^{+\bullet}$. The rate constant calculations were based on the $\mathrm{CCSD}(\mathrm{T}) / \mathrm{CBS}+\mathrm{ZPVE}$ TS energies (150.5 and $153.6 \mathrm{~kJ} \mathrm{~mol}^{-1}$ relative to $\mathbf{Z 1}^{+\bullet}$ and $\mathbf{Z 2}^{+\bullet}$, respectively) (b) TST unimolecular rate constant $\left(\log k, \mathrm{~s}^{-1}\right)$ for the isomerization of $\mathbf{Z 1}^{+\bullet}$ to $\mathbf{Z 2}^{+\bullet}$. Tunneling corrections were obtained for the TS imaginary frequency, $|v|=1917 \mathrm{~cm}^{-1}$.

Figure S9. (a) UVPD action spectrum of the $m / z 125$ fragment ion by NO loss from $\mathbf{Z}^{+\bullet}$.

Calculated vibronic spectra of (b) the $\mathrm{N}-1 \mathrm{H}\left(\mathbf{Z 8}^{+}\right)$and (c) O-2-H $\left(\mathbf{Z 1 0}^{+}\right)$isomers from TD-DFT M06-2X/6-31+G(d,p) calculations at $350 \mathrm{~K}$. 
Figure S10. (a) TST unimolecular rate constants $\left(\log k, \mathrm{~s}^{-1}\right)$ for the forward $(k)$ and reverse $\left(k_{\text {rev }}\right)$ isomerization of $\mathbf{P 1}^{+\bullet}$ to $\mathbf{P 2}^{+\bullet}$. The rate constant calculations were based on the CCSD(T)/CBS + ZPVE TS energies (178 and $159 \mathrm{~kJ} \mathrm{~mol}^{-1}$ relative to $\mathbf{P 1}^{+\bullet}$ and $\mathbf{P 2}^{+\bullet}$, respectively) and included tunneling corrections for the TS imaginary frequency, $|v|=1827 \mathrm{~cm}^{-1}$. (b) Calculated mole fraction ratio $x\left(\mathbf{Z 2}^{+\bullet}\right) / x\left(\mathbf{Z 1}^{+\bullet}\right)$.

Figure S11. M06-2X/6-31+G(d,p) optimized structures of neutral Z and P molecules.

Figure S12. TST rate constants for thermal isomerization of gas-phase $[\mathrm{Cu}(\mathrm{tpy}) \mathbf{Z 1 b}]^{2+\bullet}$ to $\left[\mathrm{Cu}(\text { tpy)Z2b }]^{2+\bullet}\right.$. Tunneling corrections were for the TS imaginary frequency, $|v|=1854 \mathrm{~cm}^{-1}$.

Scheme S1. Isomerizations of $\mathbf{P 1}^{+\bullet}-\mathbf{P 4}^{+\bullet}$. The energies in parentheses $\left(\mathrm{kJ} \mathrm{mol}^{-1}\right)$ are from $\mathrm{CCSD}(\mathrm{T}) / \mathrm{CBS}+\mathrm{ZPVE}$ calculations (Table 1 , main text) relative to $\mathbf{P 1}^{+\bullet}$.

Scheme S2. Alternative, higher-energy, reaction scheme for loss of HO-CN from $\mathbf{P 2}^{+\bullet}$. The energies in parentheses $\left(\mathrm{kJ} \mathrm{mol}^{-1}\right)$ are from CCSD(T)/CBS + ZPVE calculations (Table 1, main text) relative to $\mathbf{P} \mathbf{1}^{+\bullet}$.

Table S1. High-Resolution Mass Spectrometry Data 

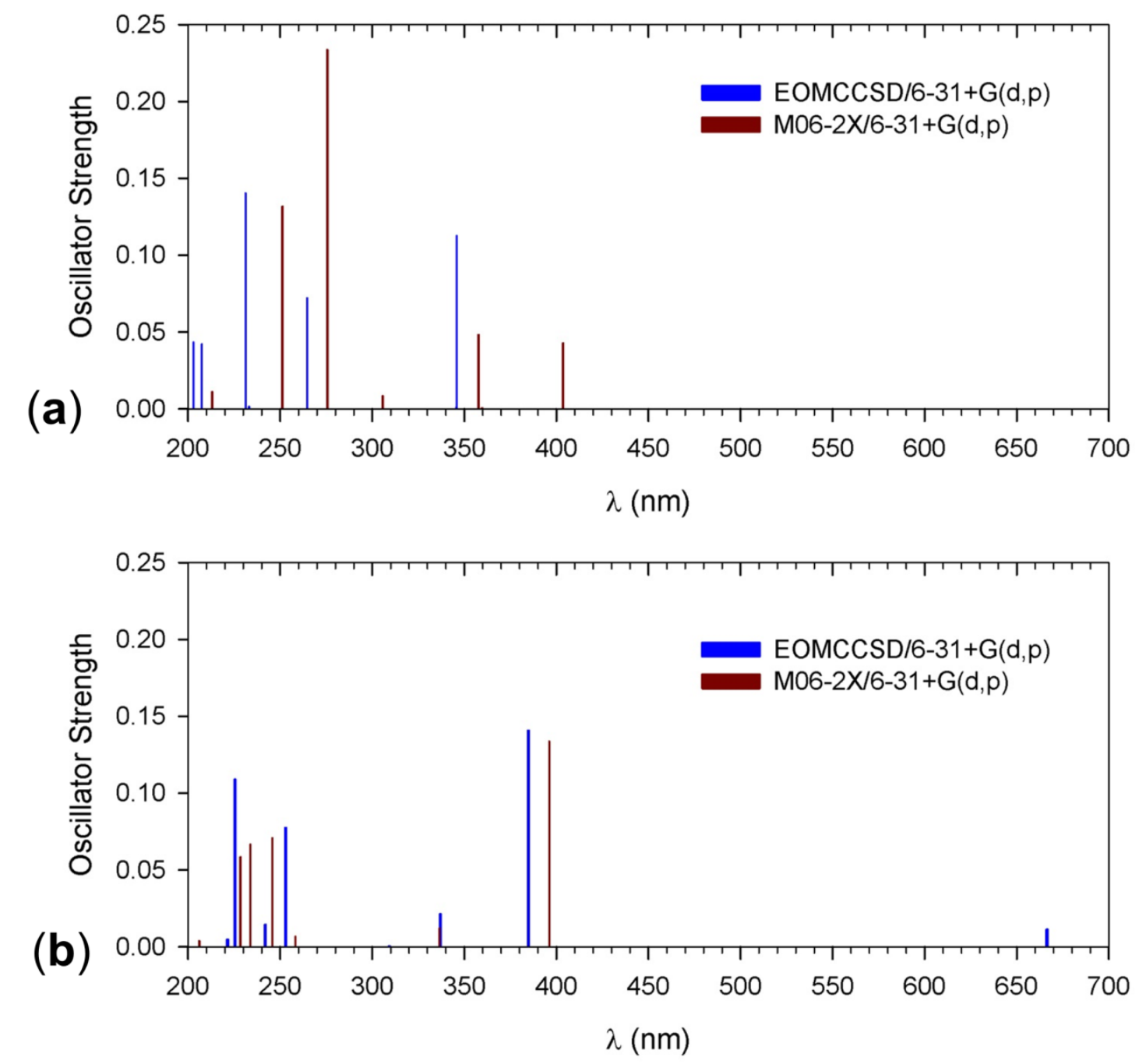

Figure S1. Electronic transitions in (a) $\mathbf{P 1}^{+\bullet}$ and (b) $\mathbf{P 4}^{+\bullet}$ calculated by EOMCCSD $/ 6-31+\mathrm{G}(\mathrm{d}, \mathrm{p}$ ) (blue lines) and TD-DFT M06-2X/6-31+G(d,p) (brown lines). 

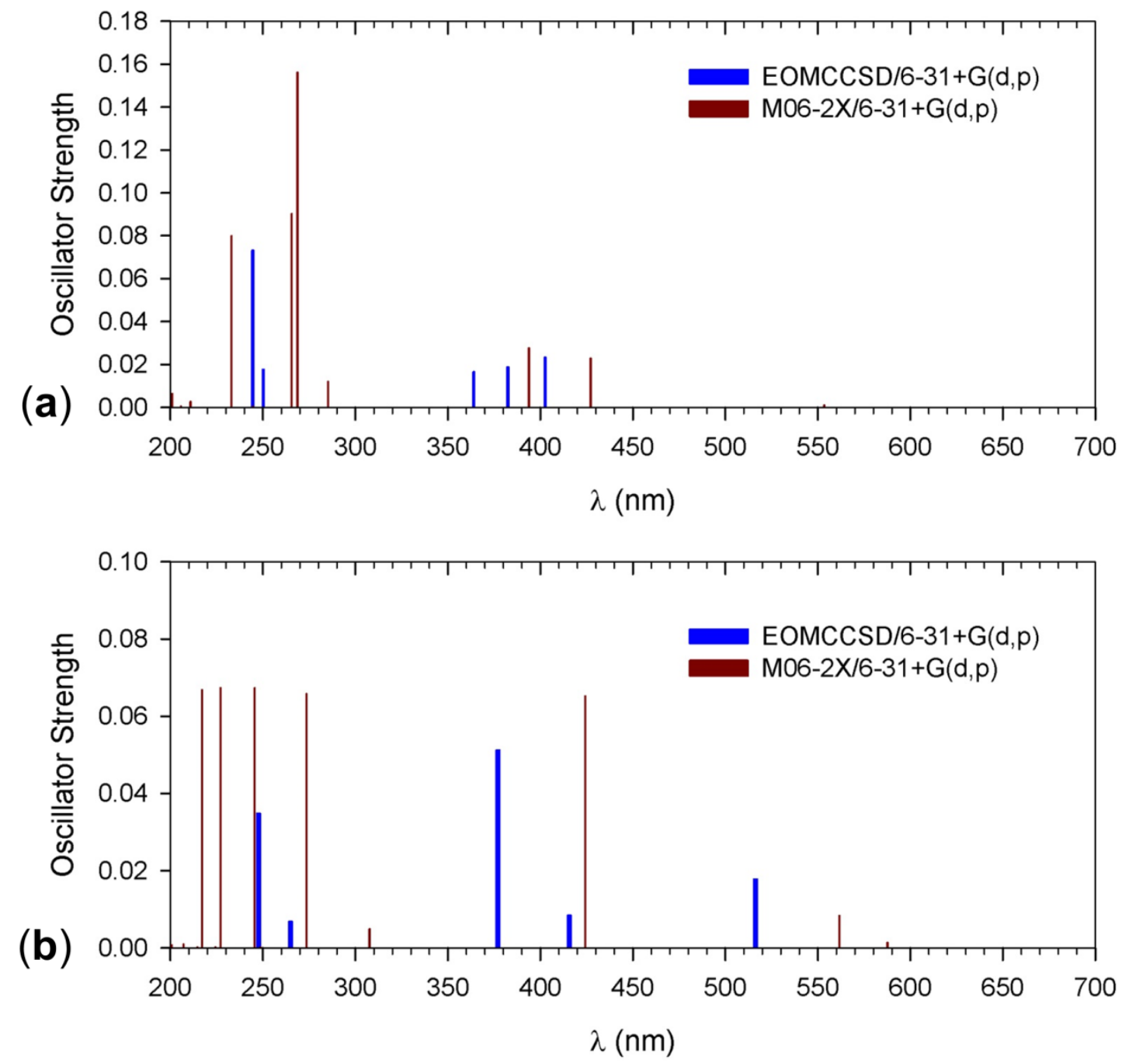

Figure S2. Electronic transitions in (a) $\mathbf{Z 1}^{+\bullet}$ and (b) $\mathbf{Z 2}^{+\bullet}$ calculated by EOMCCSD/6$31+\mathrm{G}(\mathrm{d}, \mathrm{p})$ (blue lines) and TD-DFT M06-2X/6-31+G(d,p) (brown lines). 

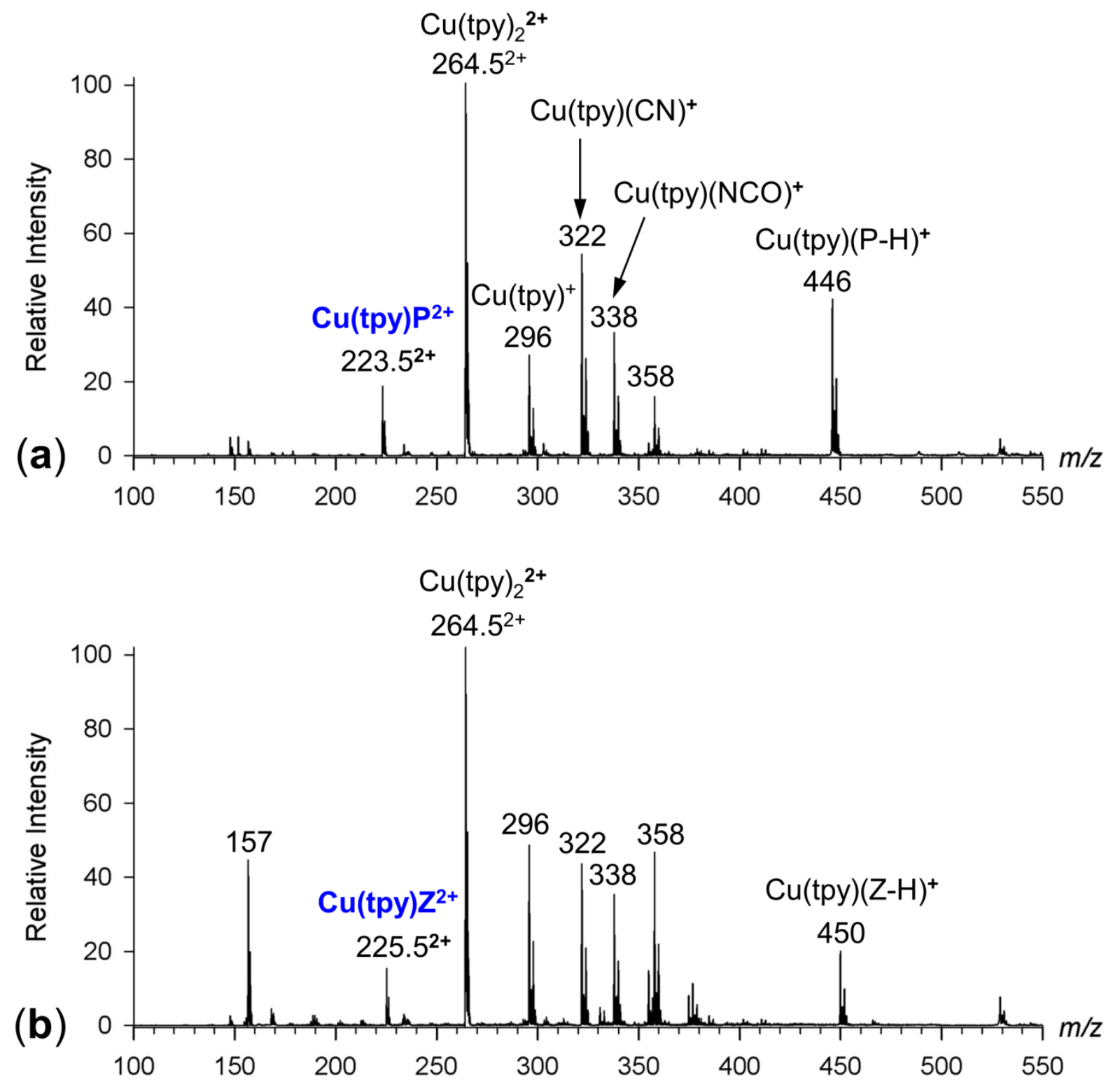

Figure S3. Electrospray mass spectra of aqueous-acetonitrile solutions of equimolar mixtures of $\mathrm{Cu}\left(\mathrm{NO}_{3}\right)_{2}, 2: 2^{\prime}, 6$ ':2"-terpyridine (tpy), and (a) imidazo[1,2-a]-1,3,5-triazine (P) and (b) 6-amino5-nitro-1H pyrid-2-one $(\mathrm{Z})$. 

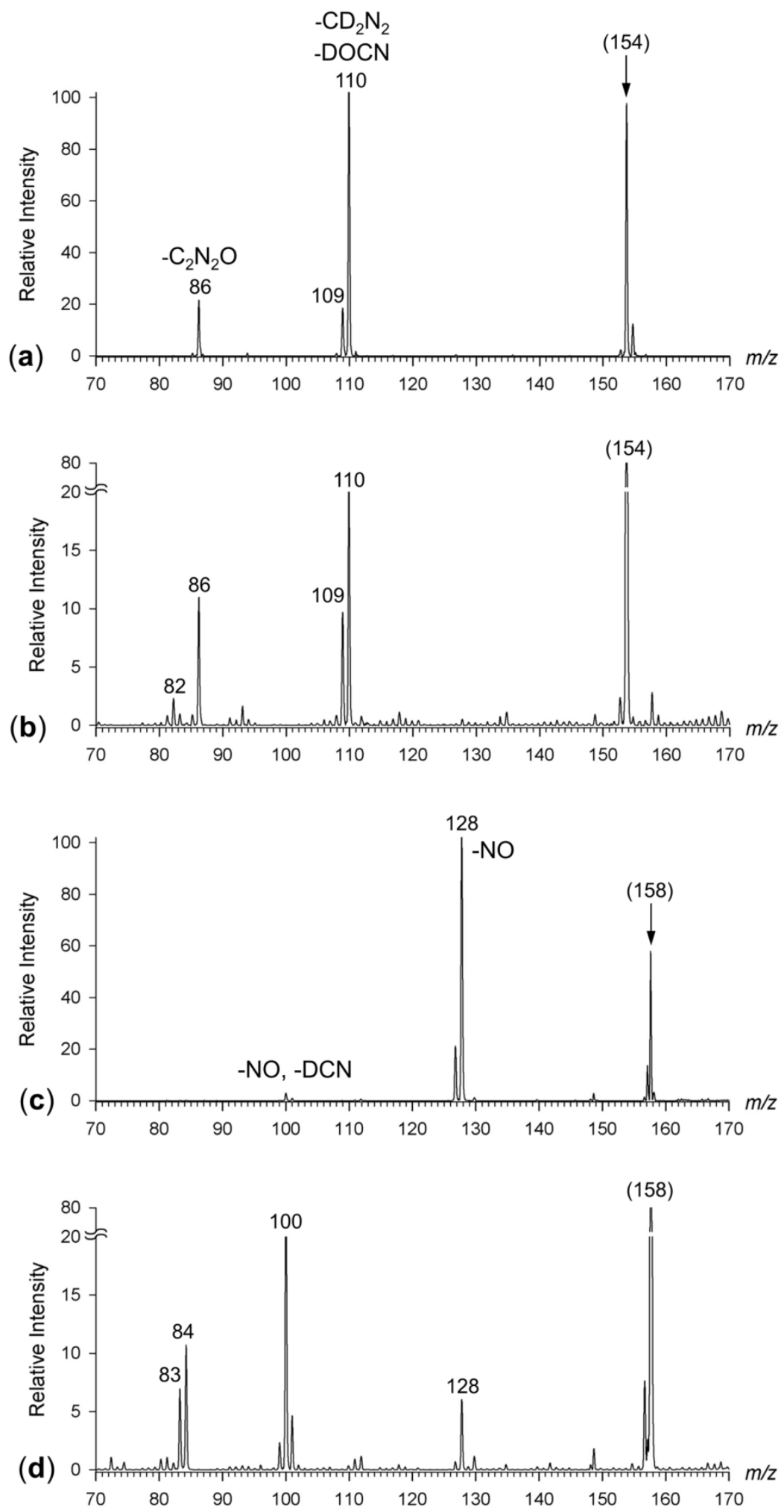

Figure S4. (a) CID-MS $\mathrm{MS}^{3}$ spectrum of $\mathrm{D}_{3}-\mathbf{P}^{+\bullet}$; (b) UVPD (270 nm)-MS $\mathrm{MS}^{3}$ spectrum of $\mathrm{D}_{3}-\mathbf{P}^{+\bullet}$; (c) CID-MS ${ }^{3}$ spectrum of $\mathrm{D}_{3}-\mathbf{Z}^{+\bullet}$; (d) UVPD (270 nm)-MS ${ }^{3}$ spectrum of $\mathrm{D}_{3}-\mathbf{Z}^{+\bullet}$. 
(a)

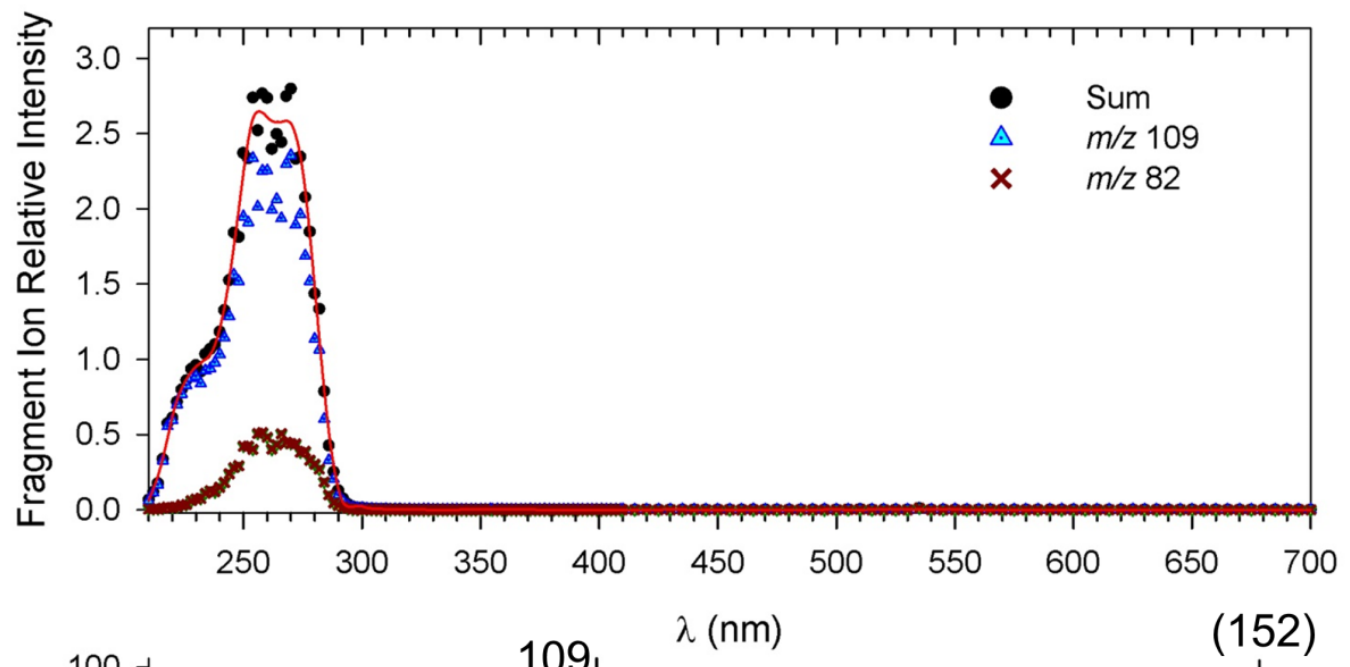

(b)

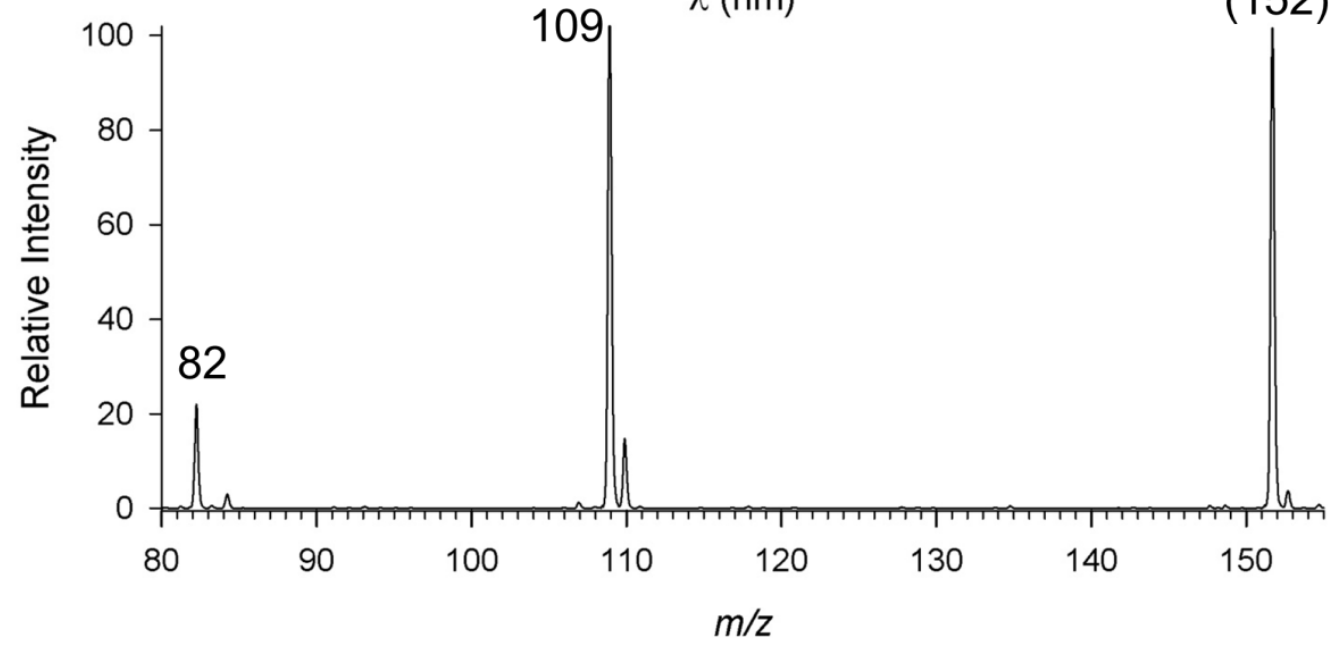

(c)

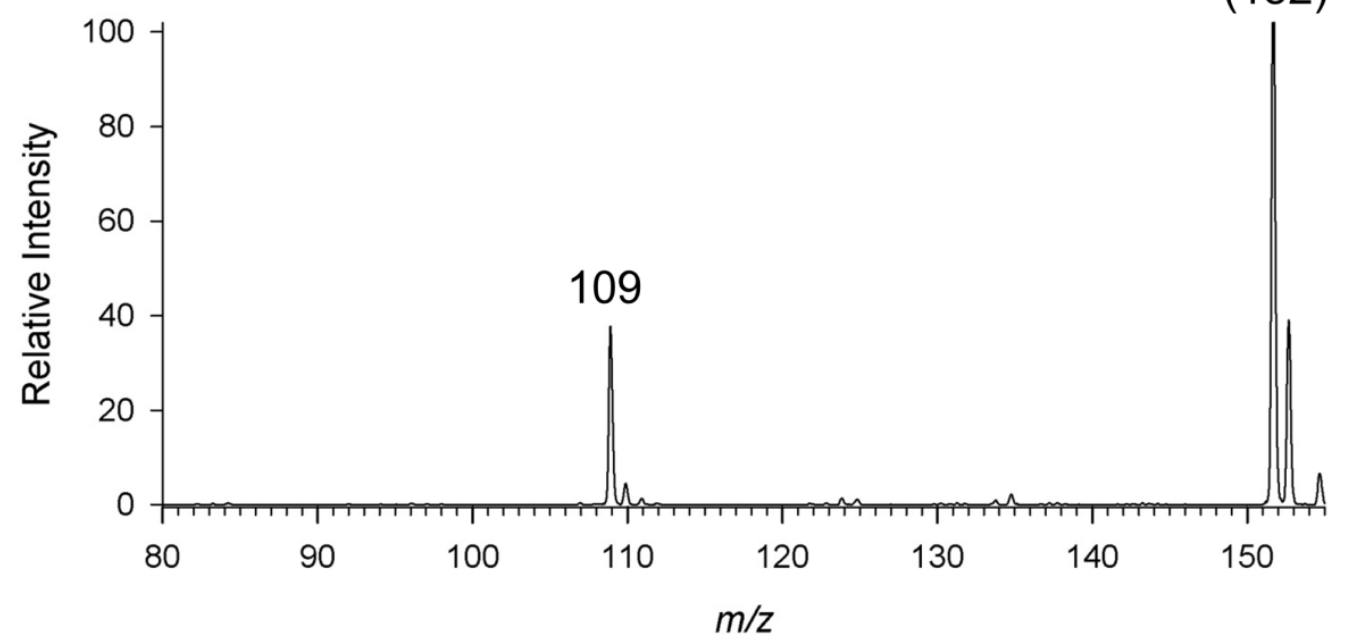

Figure S5. (a) Action spectrum of $(\mathrm{P}+\mathrm{H})^{+}$at $m / z$ 152. (b) UVPD-MS ${ }^{2}$ spectrum of $(\mathrm{P}+\mathrm{H})^{+}$at $270 \mathrm{~nm}$. (c) CID-MS ${ }^{2}$ spectrum of $(\mathrm{P}+\mathrm{H})^{+}$. 

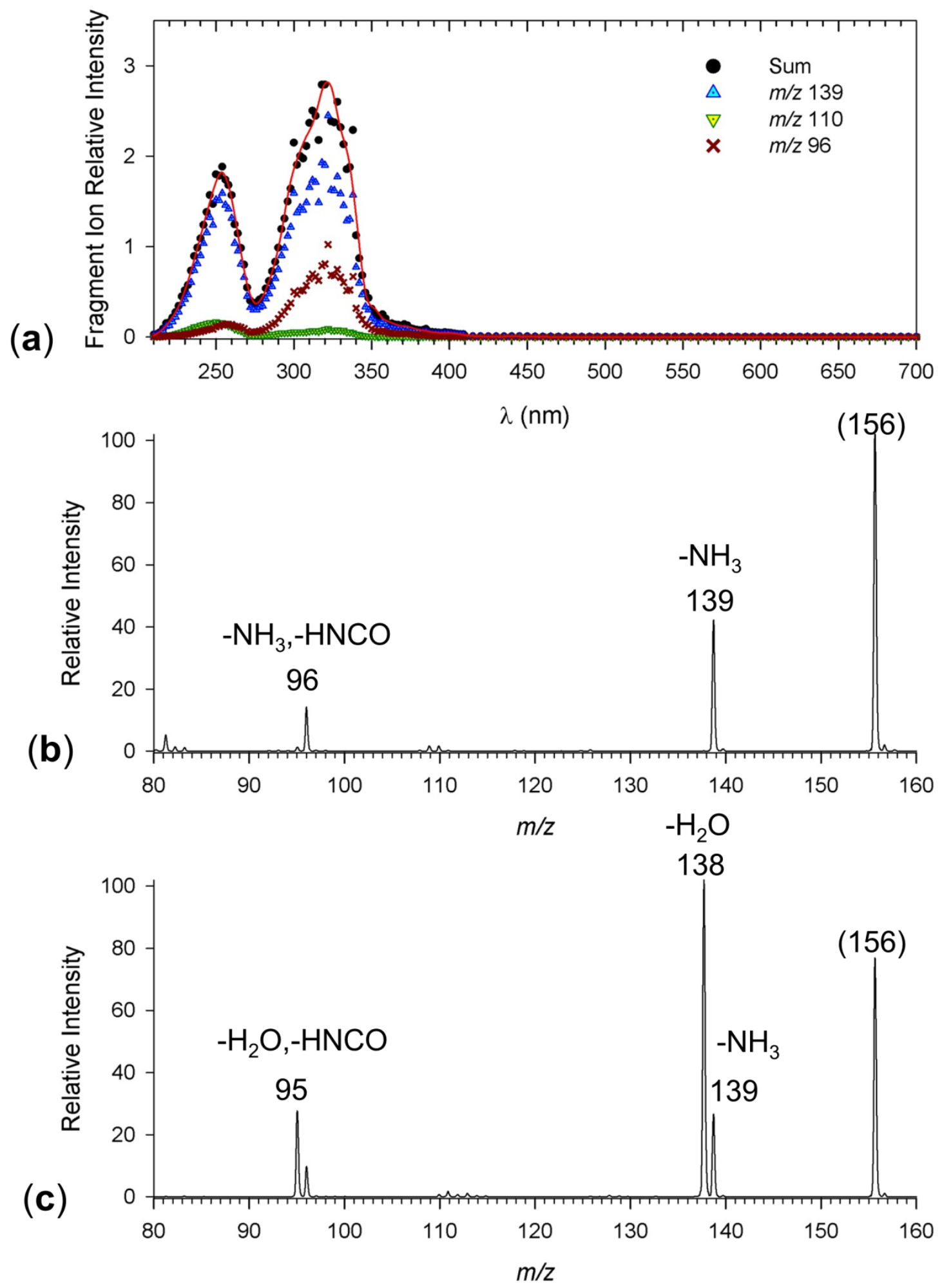

Figure S6. (a) Action spectrum of $(\mathrm{Z}+\mathrm{H})^{+}$at $m / z$ 156. (b) UVPD-MS ${ }^{2}$ spectrum of $(\mathrm{Z}+\mathrm{H})^{+}$at $300 \mathrm{~nm}$. (c) CID-MS ${ }^{2}$ spectrum of $(\mathrm{Z}+\mathrm{H})^{+}$. 

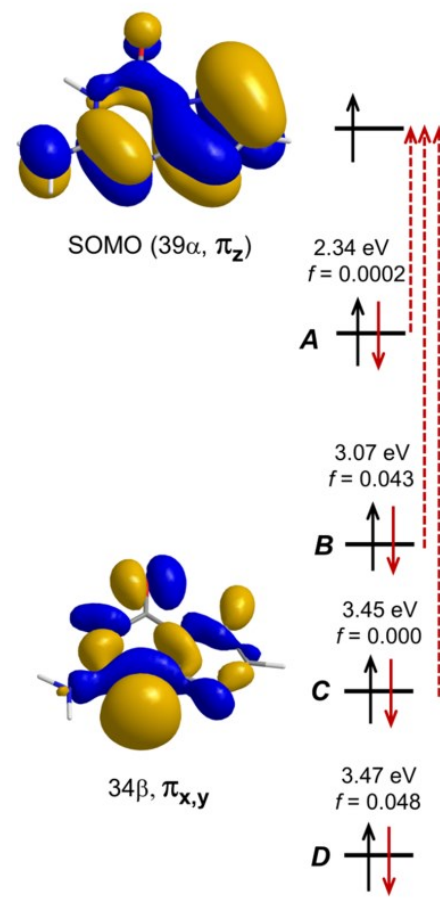

P1+•
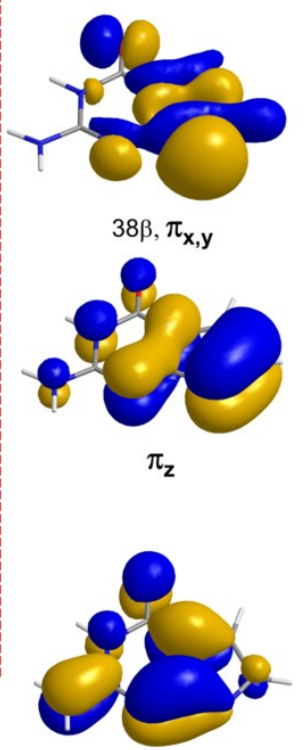

$\pi_{\mathbf{z}}$
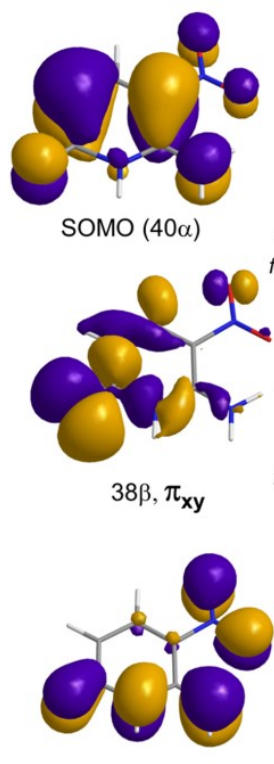

$39 \beta, \pi_{\mathbf{z}}$

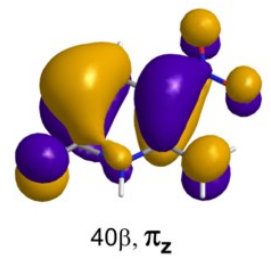

$1.79 \mathrm{eV}:$
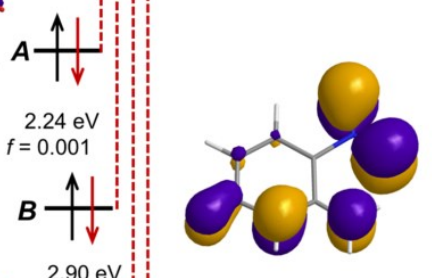

$37 \beta, \pi_{\mathbf{z}}$

$f=0.023$

$D \uparrow \downarrow$

$3.15 \mathrm{eV}$
$f=0.028$

$F \stackrel{\uparrow}{\uparrow}$ $\mathrm{Z1}^{+\bullet}$

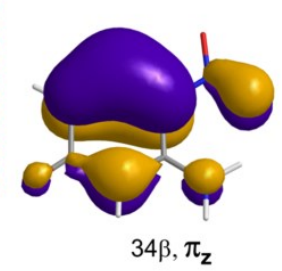

$34 \beta, \pi_{z}$

Figure S7. Molecular-orbital representation of excited states and electron transitions in $\mathbf{P 1}^{+\bullet}$ (left panel) and $\mathbf{Z 1}^{+\bullet}$ (right panel). Excitation energies and oscillator strength data are from M062X/6-31+G(d,p) TD-DFT calculations. 

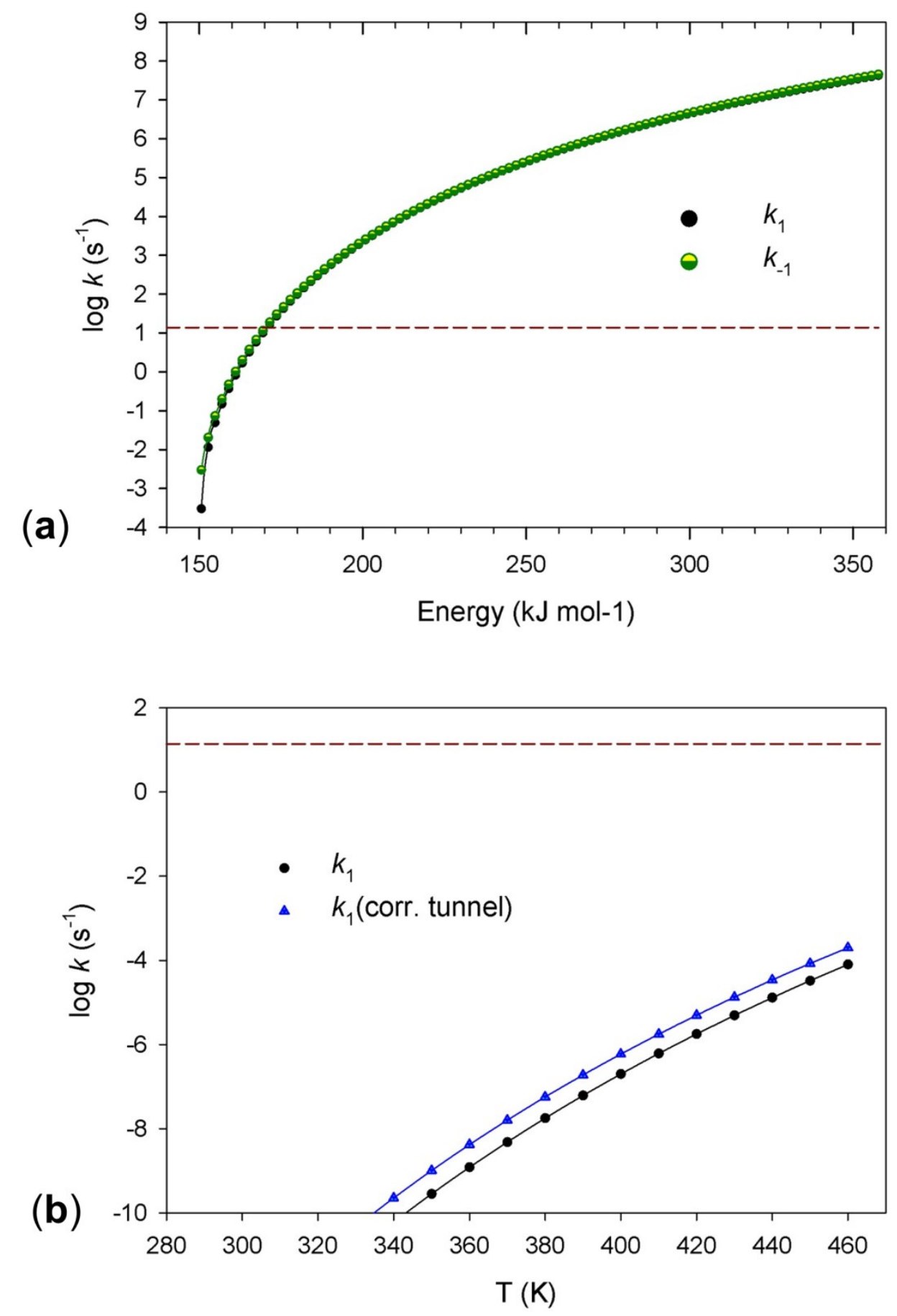

Figure S8. (a) RRKM unimolecular rate constants $\left(\log k, \mathrm{~s}^{-1}\right)$ for the forward $\left(k_{1}\right)$ and reverse $\left(k_{-1}\right)$ isomerization of $\mathbf{Z 1}^{+\bullet}$ to $\mathbf{Z 2}^{+\bullet}$. The rate constant calculations were based on the $\mathrm{CCSD}(\mathrm{T}) / \mathrm{CBS}+\mathrm{ZPVE}$ TS energies (150.5 and $153.6 \mathrm{~kJ} \mathrm{~mol}^{-1}$ relative to $\mathbf{Z 1}^{+\bullet}$ and $\mathbf{Z 2}^{+\bullet}$, respectively) (b) TST unimolecular rate constant $\left(\log k, \mathrm{~s}^{-1}\right)$ for the isomerization of $\mathbf{Z 1}^{+\bullet}$ to $\mathbf{Z 2}^{+\bullet}$. Tunneling corrections were obtained for the TS imaginary frequency, $|v|=1917 \mathrm{~cm}^{-1}$. 
(a)

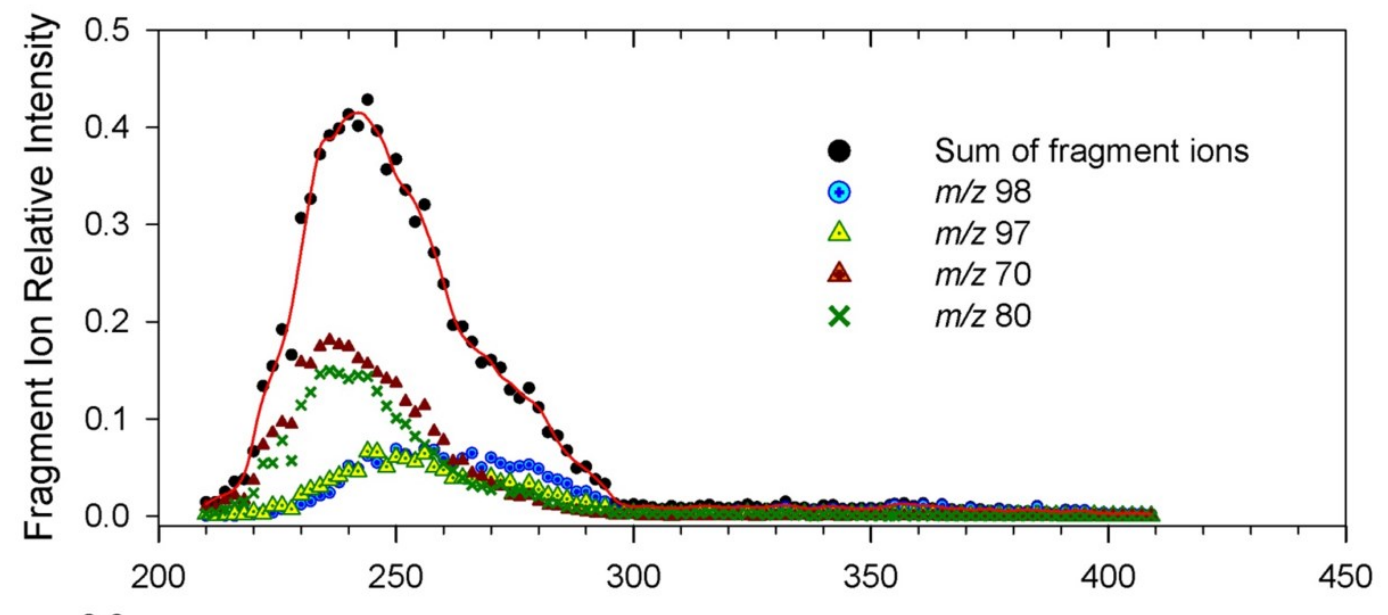

(b)

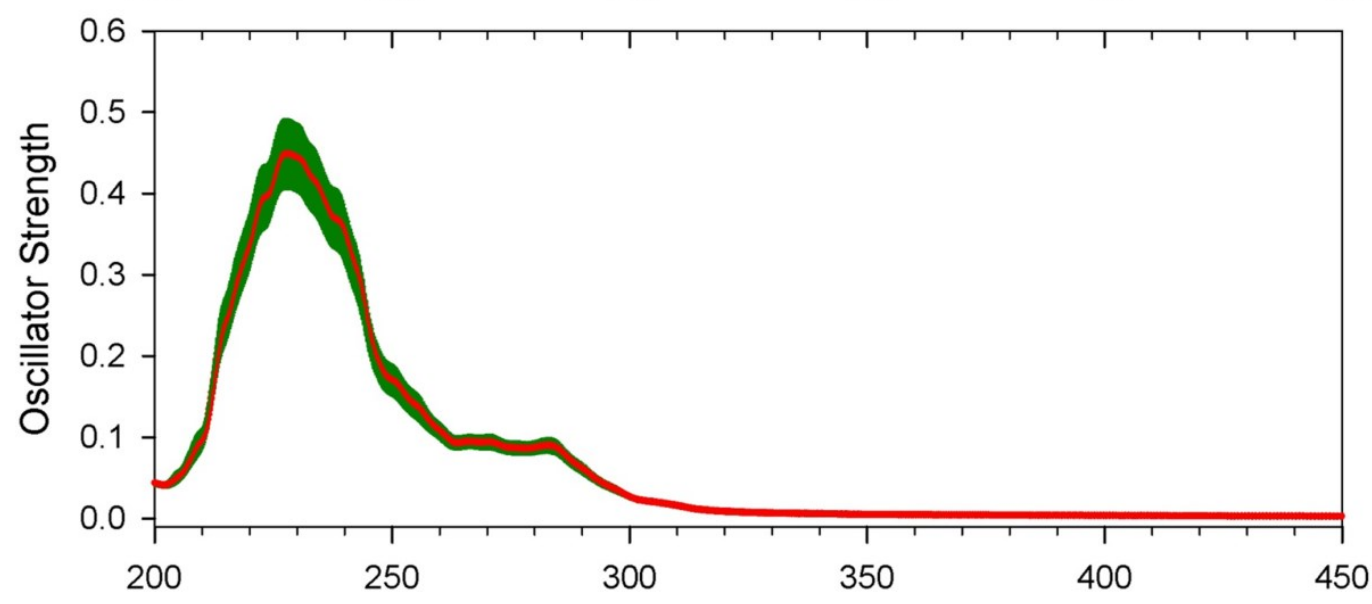

(c)

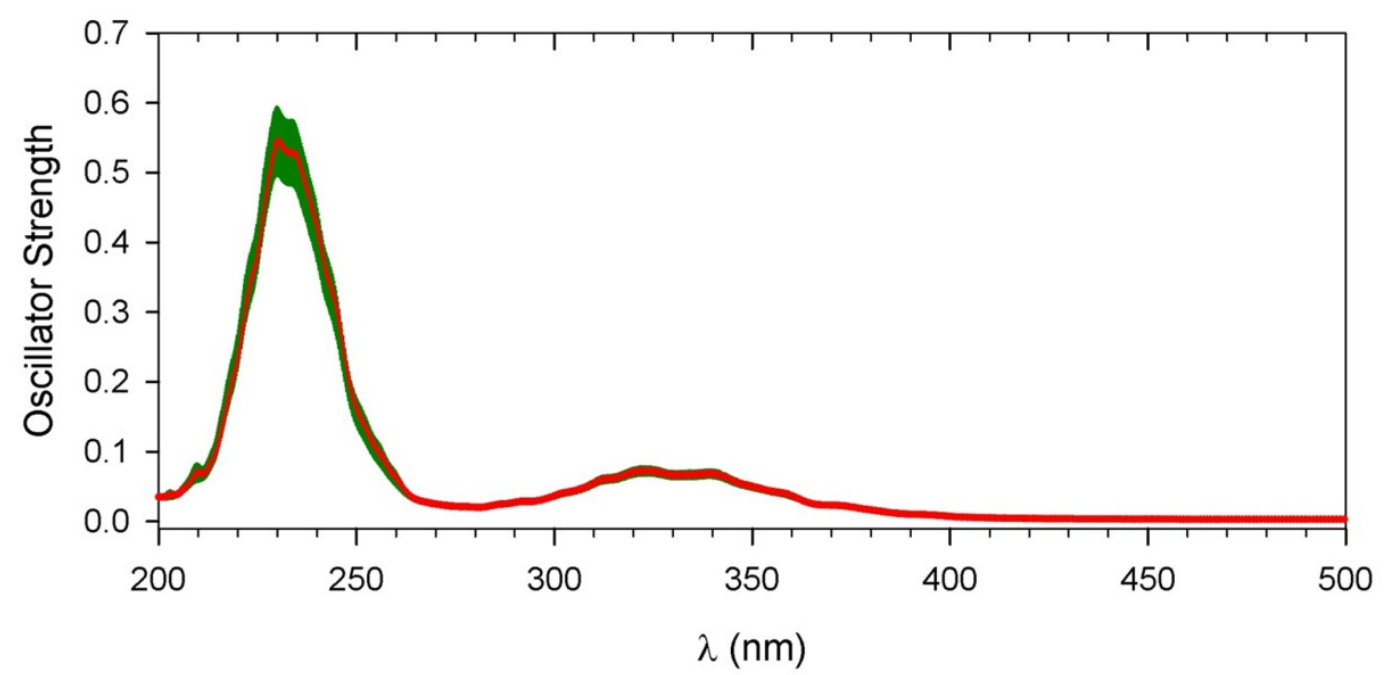

Figure S9. (a) UVPD action spectrum of the $m / z 125$ fragment ion by NO loss from $\mathbf{Z}^{+\bullet}$. Calculated vibronic spectra of (b) the $\mathrm{N}-1 \mathrm{H}\left(\mathbf{Z 8}^{+}\right)$and (c) $\mathrm{O}-2-\mathrm{H}\left(\mathbf{Z 1 0}^{+}\right)$isomers from TD-DFT M06-2X/6-31+G(d,p) calculations at $350 \mathrm{~K}$. 

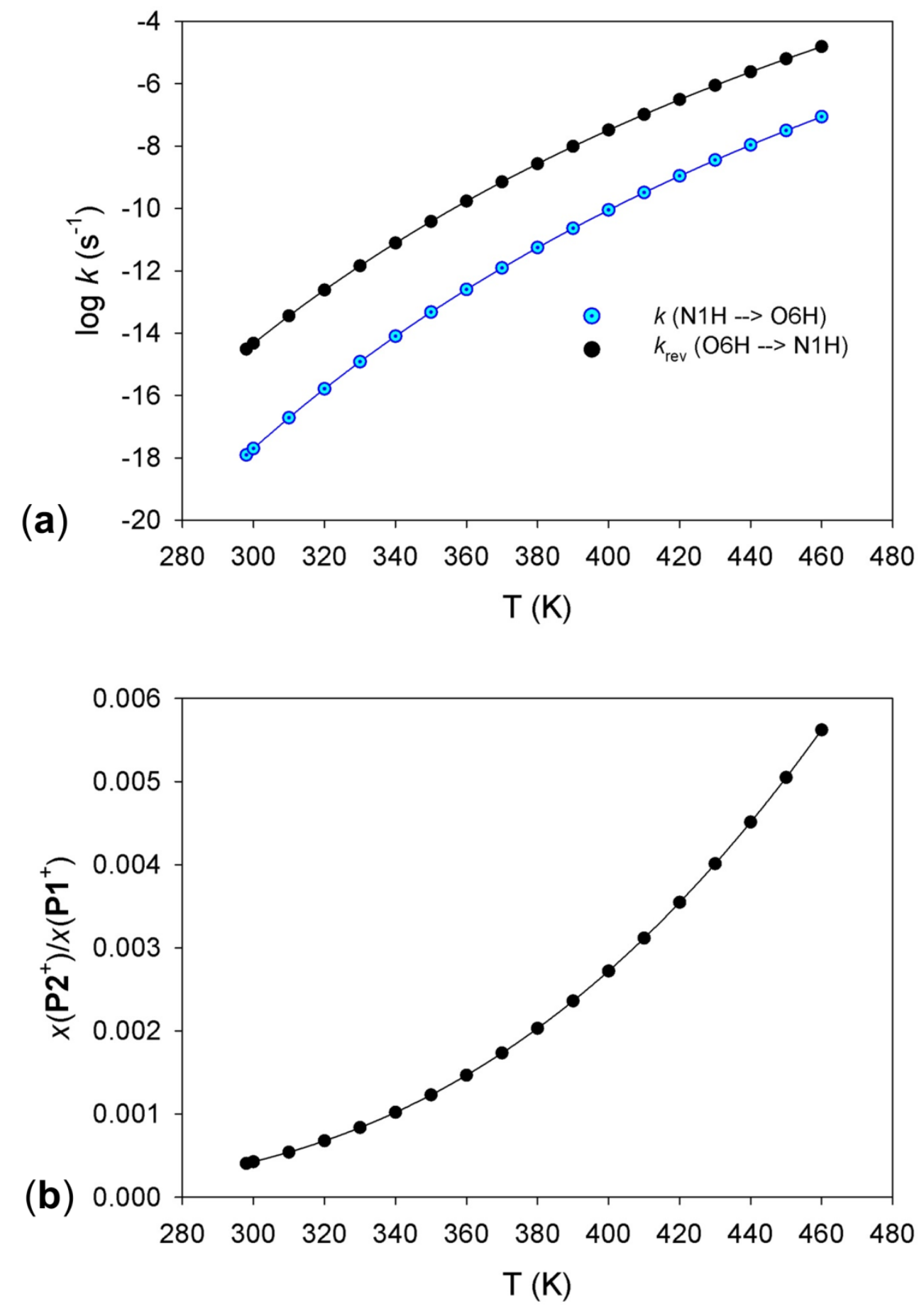

Figure S10. (a) TST unimolecular rate constants $\left(\log k, \mathrm{~s}^{-1}\right)$ for the forward $(k)$ and reverse $\left(k_{\text {rev }}\right)$ isomerization of $\mathbf{P 1}^{+\bullet}$ to $\mathbf{P 2}^{+\bullet}$. The rate constant calculations were based on the CCSD(T)/CBS + ZPVE TS energies (178 and $159 \mathrm{~kJ} \mathrm{~mol}^{-1}$ relative to $\mathbf{P 1}^{+\bullet}$ and $\mathbf{P 2}^{+\bullet}$, respectively) and included tunneling corrections for the TS imaginary frequency, $|v|=1827 \mathrm{~cm}^{-1}$. (b) Calculated mole fraction ratio $x\left(\mathbf{Z 2}^{+\bullet}\right) / x\left(\mathbf{Z 1}^{+\bullet}\right)$. 
<smiles>CC1CN(C)C(C)N2C(C)OC(O)C12</smiles>

Z1

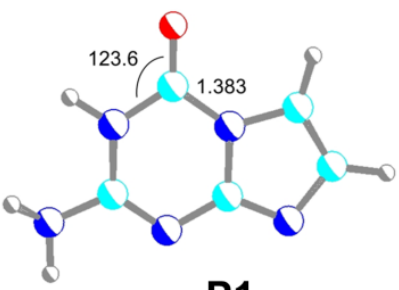

P1

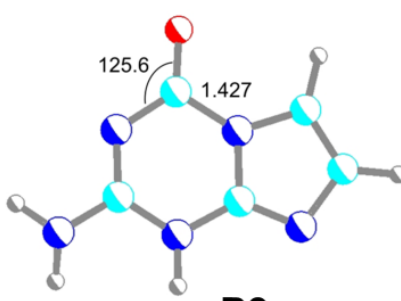

P3<smiles>CCN1CC(C)N2CN(CC)C(C)OCC2C1</smiles>

Z2
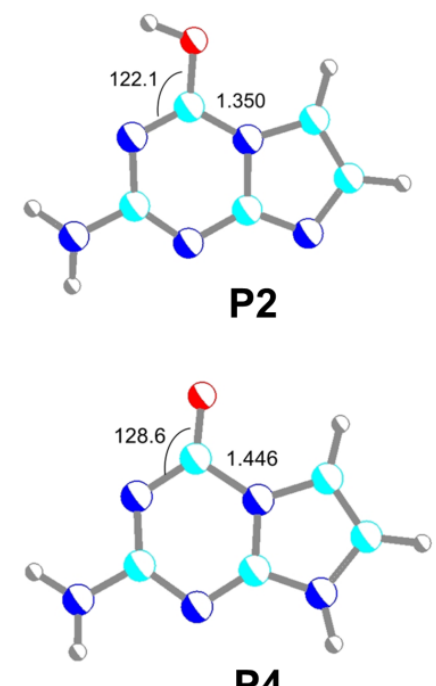

P4
Figure S11. M06-2X/6-31+G(d,p) optimized structures of neutral $\mathrm{Z}$ and $\mathrm{P}$ molecules.

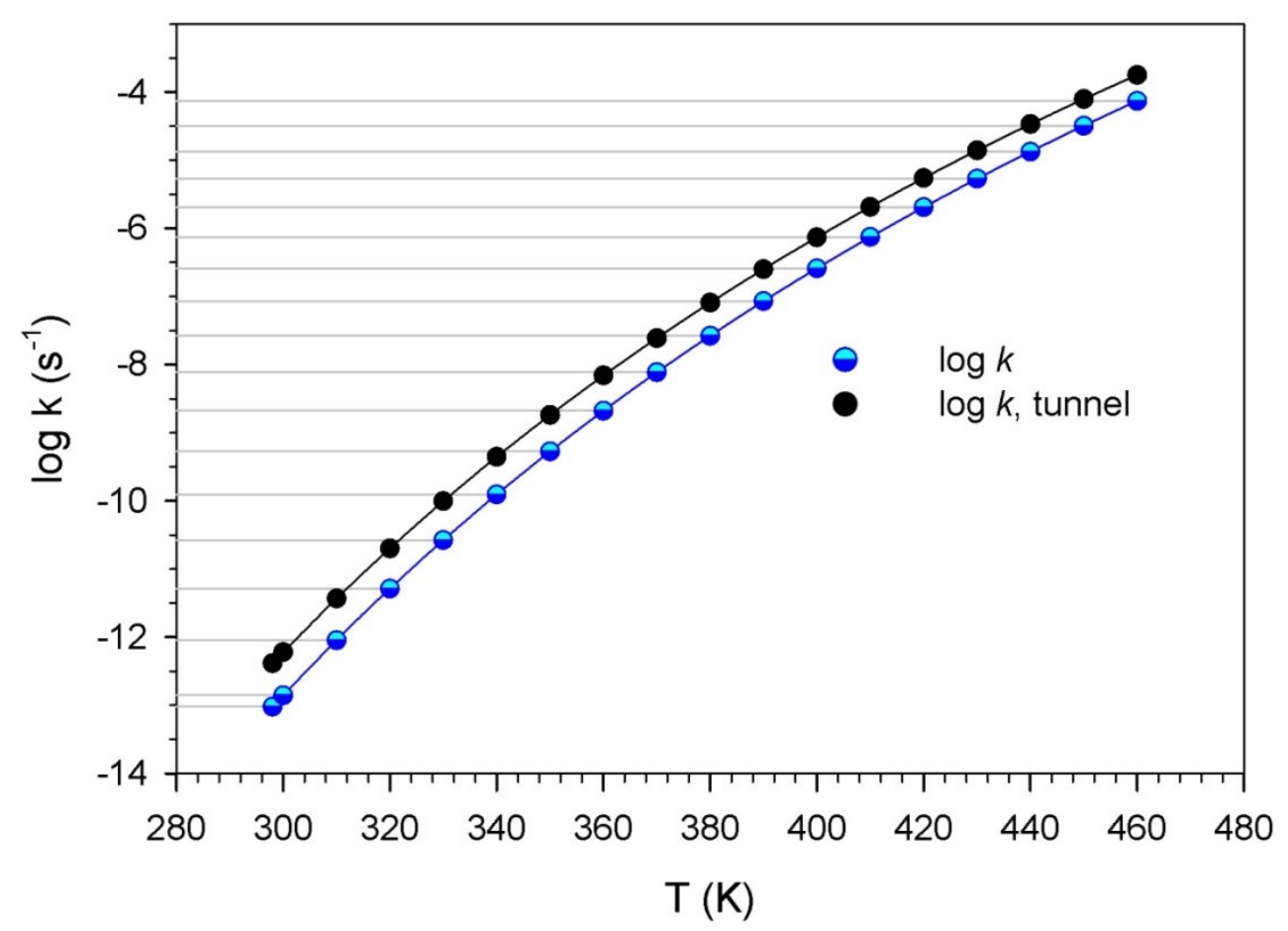

Figure S12. TST rate constants for thermal isomerization of gas-phase $[\mathrm{Cu}(\mathrm{tpy}) \mathbf{Z 1 b}]^{2+\bullet}$ to $\left[\mathrm{Cu}(\text { tpy)Z2b }]^{2+\bullet}\right.$. Tunneling corrections were for the TS imaginary frequency, $|v|=1854 \mathrm{~cm}^{-1}$. 

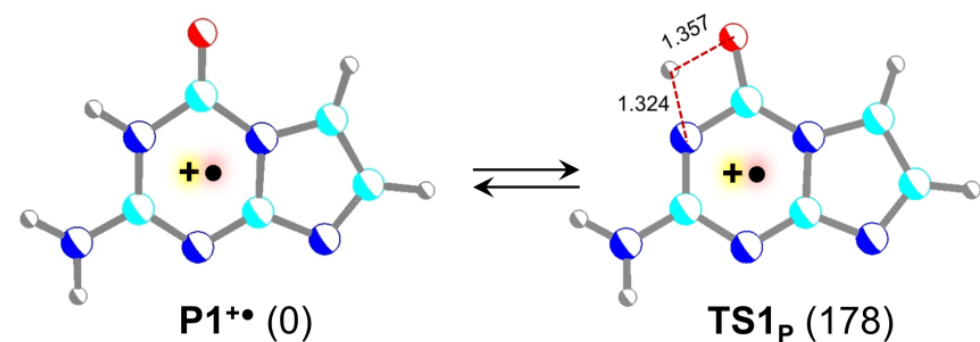

$\mathrm{TS1}_{\mathrm{P}}(178)$

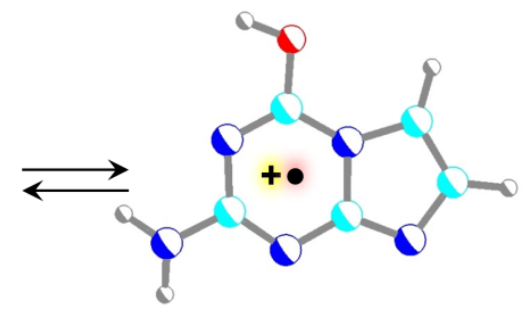

$\mathbf{P 2}^{+\bullet}(19)$

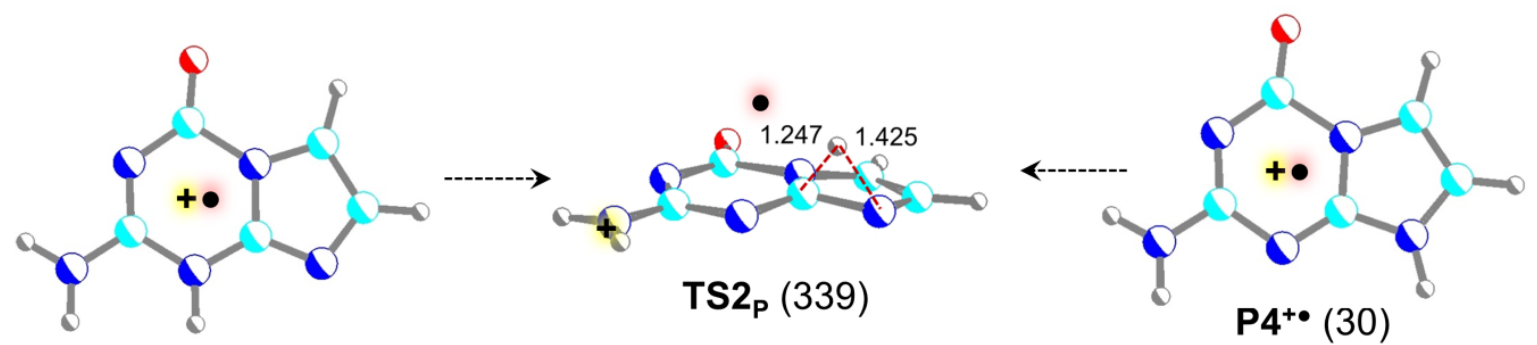

P3 $^{+\bullet}(46)$

Scheme S1. Isomerizations of $\mathbf{P 1}^{+\bullet}-\mathbf{P 4}^{+\bullet}$. The energies in parentheses $\left(\mathrm{kJ} \mathrm{mol}^{-1}\right)$ are from $\operatorname{CCSD}(\mathrm{T}) / \mathrm{CBS}+\mathrm{ZPVE}$ calculations (Table 1 , main text) relative to $\mathbf{P 1}^{+} \bullet$.

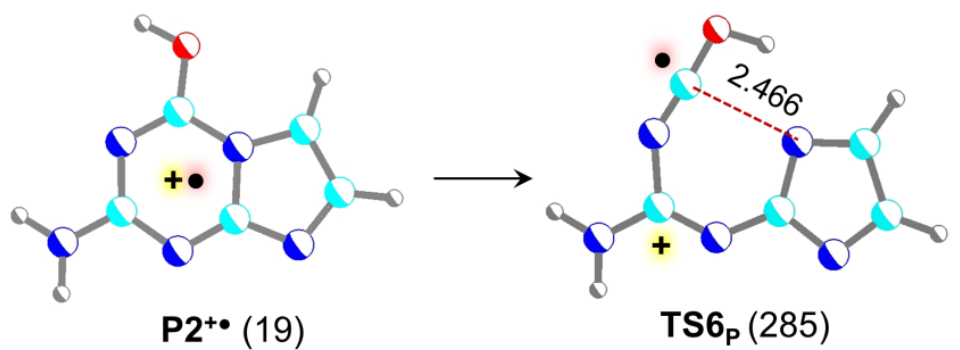

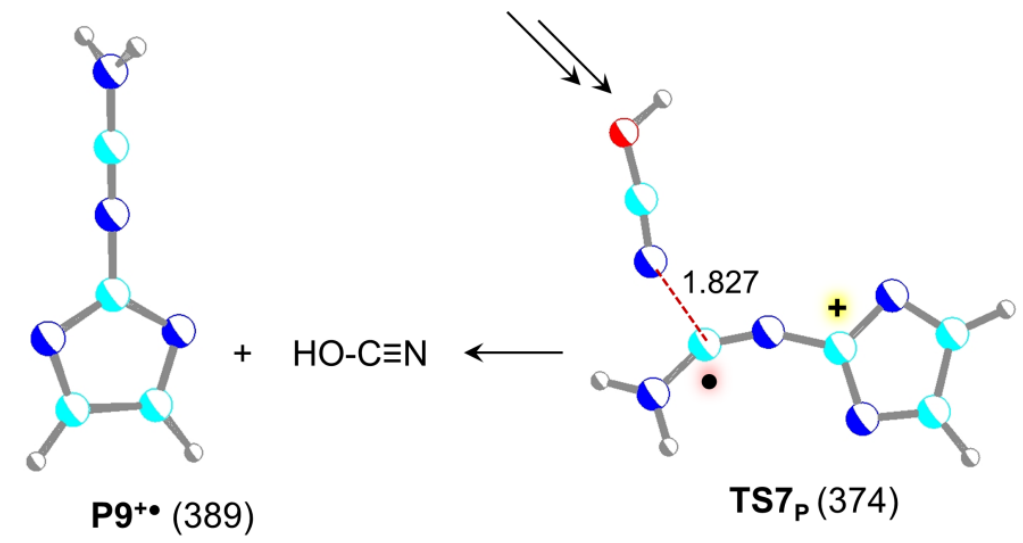

Scheme S2. Alternative, higher-energy, reaction scheme for loss of HO-CN from $\mathbf{P 2}^{+\bullet}$. The energies in parentheses $\left(\mathrm{kJ} \mathrm{mol}^{-1}\right)$ are from CCSD(T)/CBS + ZPVE calculations (Table 1, main text) relative to $\mathbf{P 1}^{+\bullet}$. 
Table S1. High-Resolution Mass Spectrometry Data.

Ion $m / z \quad$ Formula $\quad$ Error (millimass units)

\begin{tabular}{lll}
\hline & & \\
338.0208 & $\mathrm{C}_{16} \mathrm{H}_{11} \mathrm{~N}_{4} \mathrm{O}^{63} \mathrm{Cu}$ & -1.5 \\
296.0230 & $\mathrm{C}_{15} \mathrm{H}_{11} \mathrm{~N}_{3}{ }^{63} \mathrm{Cu}$ & -1.3 \\
223.5355 & $\mathrm{C}_{20} \mathrm{H}_{16} \mathrm{~N}_{8} \mathrm{O}^{63} \mathrm{Cu}^{2+}$ & -1.3 \\
151.0480 & $\mathrm{C}_{5} \mathrm{H}_{5} \mathrm{~N}_{5} \mathrm{O}$ & -0.9 \\
109.0500 & $\mathrm{C}_{4} \mathrm{H}_{5} \mathrm{~N}_{4}$ & -0.9 \\
& & \\
151.0479 & $\mathrm{C}_{5} \mathrm{H}_{5} \mathrm{~N}_{5} \mathrm{O}$ & -1.0 \\
109.0262 & $\mathrm{C}_{4} \mathrm{H}_{3} \mathrm{~N}_{3} \mathrm{O}$ & -0.9 \\
108.0422 & $\mathrm{C}_{4} \mathrm{H}_{4} \mathrm{~N}_{4}$ & -0.9 \\
83.0469 & $\mathrm{C}_{3} \mathrm{H}_{5} \mathrm{~N}_{3}$ & -0.9 \\
& & \\
225.5273 & $\mathrm{C}_{20} \mathrm{H}_{16} \mathrm{~N}_{6} \mathrm{O}_{3}{ }^{63} \mathrm{Cu}$ & -2.3 \\
155.0316 & $\mathrm{C}_{5} \mathrm{H}_{5} \mathrm{~N}_{3} \mathrm{O}_{3}$ & -0.9 \\
125.0336 & $\mathrm{C}_{5} \mathrm{H}_{5} \mathrm{~N}_{2} \mathrm{O}_{2}$ & -0.9 \\
& & \\
\hline
\end{tabular}

